\title{
Online versus Onsite Teaching Performance Analysis of an Introductory Electrical Circuit Class
}

\author{
Mohammad Amin¹, Bhaskar Sinha ${ }^{2}$, Pradip Peter Dey ${ }^{3}$ \\ $\mathbf{1 , 2 , 3}$ Department of Engineering and Computing, National University, San Diego, California, USA \\ 1 mamin@nu.edu \\ 2 bsinha@nu.edu \\ 3pdey@nu.edu
}

\begin{abstract}
Academia is adapting to the new age of online teaching and learning as the online mode has rapidly spread during the past several months. This is a significant paradigm shift and can also be viewed as an opportunity to think and experiment outside the box and question the traditional age-old ways of functioning in the onsite mode. As expected, there is continuous need and strong demand for innovative flexible online activities that promote learning. Currently, most academic institutions are in the process of either evaluating or implementing the new online options and tools for their programs. This paper compares the assessment data for online and onsite offerings of electrical circuit STEM classes during 2007-2021 and suggests that online mode is as good as or better than onsite mode. Future research areas are recommended that may contribute to understanding these trends and results in other areas of engineering and computer science.
\end{abstract}

Keywords - Assessment, engineering, learning modality, STEM

\section{INTRODUCTION AND BACKGROUND}

The educational space is shifting rapidly, and possible alternatives to traditional onsite in-person face-to-face education model are being studied, analyzed, and evaluated. One of the possible options is a robust online system, maybe asynchronous, that performs as good as or better than the traditional onsite model. The results, as presented in this paper, clearly indicate that the engineering students at National University (NU @ www.nu.edu) who took the fundamental electrical circuit classes during the period 2007-2020 performed better in the online mode and they learned equally or better in online circuit classes than in the traditional onsite circuit classes.

This online paradigm is not only for the benefit of teaching and learning, but also as a new and profitable business model for academia. This is due to, among many other reasons, the reduction in required resources and the availability of qualified faculty. Challenges and opportunities for robust online educational environments are being critically examined and evaluated. There are many challenges and vulnerabilities, that may lead to a student doing poorly in a technology based online class, compared to the students' performance in a traditional face-to-face on-site environment with a teacher, but learning boils down to absorbing the content, and as instructors design the course content and the delivery method that help support students as they learn, online instruction can turn out to be very effective. Many Science, Technology, Engineering, and Math (STEM) educators are now attempting to learn how to teach courses online. This is a special challenge in this technical space due to the requirements of hands-on laboratories. National University started offering online programs more than twelve years ago and the authors of this paper got engaged in online teaching activities since the start of this effort. In the beginning, there was some reluctance to the adoption of this new education paradigm and the resulting quality of online education was questioned.

Online educational systems involves courses that are $100 \%$ virtual, including massively open online courses (MOOCs). Online learning, or virtual classes offered over the internet, is contrasted with traditional courses taken in a brick-and-mortar school building. It is the latest development in distance education that began in the mid-1990s with the spread of the internet and the World Wide Web. Learner experience is typically asynchronous but may also incorporate synchronous elements. Most institutions utilize a Learning Management System for the administration of online courses. As theories of distance education advance and evolve, digital technologies to support learning and pedagogy continue to transform as well [1]. Correspondence courses started in the 1800s, using parcel post to reach students who could not be on a university campus [2]. By the early 1900s, communication technologies improved significantly, and distance education took to the radio. In 1919, 
faculty at the University of Wisconsin began an amateur radio station, becoming the first licensed radio station dedicated to educational broadcasting [2]. Soon after, higher education was further advanced through the television with telecourse. The University of Iowa began to conduct experiments with television for educational purposes in the 1930s. It was not until the 1950s, when the Federal Communication Commission (FCC) began to reserve television frequencies for educational purposes, that telecourses caught the attention of the public. The value of television for education was furthered by the establishment of the Corporation for Public Broadcasting (CPB) in 1967. The CPB mission was "to encourage the growth and development of public radio and television broadcasting, including the use of such media for instructional, educational, and cultural purposes" [2 p.27]. Online learning emerged in 1982 when the Western Behavioral Sciences Institute in La Jolla, California opened its School of Management and Strategic Studies. The school employed computer conferencing to deliver a distance education program to business executives [3]. In 1989 the University of Phoenix began offering education programs through the internet. In 1993 with the entrance of the first Internet web browser, created by the University of Illinois, online learning began to flourish [4]. In 1998, the fully online programs were founded: New York University Online, Western Governor's University, the California Virtual University [4], and Trident University International [5-6].

The Educational Technology Leadership (ETL) Program, through the Graduate School of Education and Human Development at The George Washington University, offered a master's degree in 1992. The program, developed by Dr. William Lynch, originally delivered course content in association with Jones Intercable's Mind Extension University (ME/U). Classes were broadcast via satellite late at night, and students communicated through a Bulletin Board system. Their first cohort graduated in May 1994. By early 1996, Bill Robie transitioned the ETL Program to the Internet where the graduate degree program was offered completely online. He assembled a set of web-based tools and HTML pages that allowed asynchronous communication among students and faculty, the delivery of lectures, drop boxes for assignments, and other features that have since become the core toolkit for course management systems [5-6].

Radford noted that in the year 2000 only $8 \%$ of students were enrolled in online classes, but by 2008 enrollment had increased to $20 \%$ [7]. Since then, the growth of online mode of education significantly increased to nearly $30 \%$ by the fall of 2013. Literature documents that this $30 \%$ of all postsecondary students were enrolled in some form of distance education courses [8]. Although the available data on online courses and program completions are complicated and are subject to different interpretations [9], researchers have noted high rates of attrition (ranging from 20\%-50\%) among students enrolled in online courses compared to those who take traditional face-to-face in-person courses [10]. In 2020, the global coronavirus pandemic urged many academic institutions to quickly switch to the online mode of delivering content instead of in-person classes in traditional classrooms [11-14].

Online educational systems have existed for quite a while as a secondary option, with the main option being onsite inperson traditional education in academia. Now, especially with the pandemic, teaching institutions are investigating alternatives to traditional onsite education, with a renewed attention to the scope and limitations of these options. This research paper analyses the option of offering online synchronous and asynchronous courses in a highly technical STEM curriculum with some results and author reflections. It analyzes the performances and responses of students who took onsite and online offerings of an electrical circuits and systems course with the same instructor and content materials, during 2007-2020 at National University (NU). This university, at a very early stage, recognized the importance and the need of online education and started offering online degrees. In 2019, approximately $70 \%$ of its students participated online and all programs were made ready for online delivery. During the pandemic of 2020 students at NU were given the choice to join online classes. The faculty in the Department of Engineering and Computing (DOEC) at NU, are continually engaged in exploring effective teaching methods to deliver quality instructions and materials to its students in the real or virtual classrooms for efficient and successful longterm and short-term learning. Today, at NU, online education has become more popular because of its quality, accessibility, and affordability. While most universities and colleges are offering their programs online in some form, NU has, in addition, proactively made significant innovative improvements on both technology platforms and pedagogy for its online synchronous and asynchronous offerings.

The US Department of Education (DOE) has published a report based on studies in the medical education conducted during 1996-2008. They have concluded that online teaching and learning has been modestly more effective, on average, than the traditional face-to-face instructions with which the comparison has been made [15]. Babson Research Survey Group has published a report based on a survey of 2800 universities and colleges. It was concluded that the demand for online education is on the rise and the quality is improving with the advancement of technology, more faculty engagement, and administrative support [16]. Literature also mentions that the use of WhatsApp social networking and other forms of online communications among students, especially younger generation students, have significant positive impact on their learning [17]. In the past, community college students preferred to take "easy" academic subjects online and "difficult" or "important" subjects from onsite classrooms [18]. This type of notions and practices are changing as the convenience and effectiveness of online education is becoming obvious. Another study observed that STEM students learned better in a blended learning environment than in the 
online and onsite learning environment [19]. Illinois Online, offering many online degrees, claims five major benefits of online educations: 1) Career Advancement, 2) Flexible Schedule, 3) Cost Effective, 4) Self-Discipline and Responsibility, and 5) More Choice of Courses [20]. As the World Health Organization (WHO) officially declared the year 2020 as the pandemic year, teaching and learning has brought many challenges and has opened many opportunities in academia. This paradigm shift to online education is now here to stay and needs all educational institutions worldwide to accept and embrace this change. NU is currently offering all its courses online and, for most of the courses, may continue this in the future. The Online Learning Consortium has recently developed a Faculty Playbook to provide resources and guidelines for development of online course materials and delivery methods [21]. The authors of this research have also published number of reports on online teaching and learning, analyzing the effectiveness of this new academic paradigm - some of the recent publications are in the references [22-24].

\section{METHODS OF DELIVERY}

Given the enhancements and technical progress in delivery methods, the online teaching-learning environments provide a greater degree of flexibility than the traditional in-person classroom settings [25-26]. Online platforms are also more flexible and can be fine-tuned to offer more targeted features to diverse representations of student populations as more and more learners are working adults in this twenty-first century [27]. The diversity arises from networking with students outside of one's geographical space, and possibly offering a variety of perspectives on course content [28]. Courses that are presented completely online as a virtual class are primarily delivered in an asynchronous or synchronous teaching-learning format.

Asynchronous online learning environments are defined as online modes where work is supported using digital platforms in such a way that participants are not required to be online at the same time as other classmates [28-29]. Emails, threaded discussions, chats, telephone calls, and other methods of communications are possibilities and choices of asynchronous delivery [30]. For learners, this gives meaning to the anytime-anywhere appeal of online learning [31]. One of the significant benefits of an asynchronous platform is that the learners have more time at their own convenience to produce well researched content-related responses for the instructor and peer postings; they have time to find facts to support their written statements [28]. It is an accepted fact that more time to think and research leads to more permanent learning, and the additional time provides an opportunity to increase the learner's ability to process and digest the information [28]. The spelling and grammar within postings of an asynchronous environment are like that found in traditional academic writing [32]. The flip side of this learning platform, that may be considered as one of the foremost drawbacks of this delivery method, is the greater possibility for a learner to feel detached from the learning environment. Asynchronous learning is viewed as less social in nature and can cause the learner to feel isolated [28]. By providing the student a feeling of belonging to the cohort, classmates, university, or institution, will help with this feeling of isolation, and this can be accomplished to an extent through ensuring links to university support systems and the library are available, accessible, and operable [30].

Synchronous online learning environments closely resemble the traditional face-to-face learning [25][29]. Synchronous online learning takes place through digital platforms where all the learners, and the teacher, meet online and utilize the online media at the same time. When compared to asynchronous learning, synchronous online environments provide a greater sense of feeling supported, as the exchange of text or voice is immediate and feels more like a live normal conversation [25]. If platforms such as web conferencing or video chat are used, learners can hear the tone of voice used by others which may allow for greater understanding of the content [27]. As in a traditional in-person environment, online learners may feel a need to keep the conversation going, so there is a potential for focusing on the quantity of responses over the quality of content within the response [28]. However, the synchronous environment, with real-time responses, can allow the students and instructors to provide clarity to what was said, or avoid and clarify, any possible misunderstandings [25].

Based on the above online courses may be categorized into the following four groups [33]:

1. Asynchronous Massive Open Online Courses (AMOOCs): Unlimited number of participants, enabling them to learn asynchronously in their own time and at their own pace.

2. Synchronous Massive Online Open Courses (SMOOCs): The environment is like AMOOCS, except that the students participate synchronously and in real-time.

3. Asynchronous Small Private Online Courses (ASPOCs): Here the number of students is limited, and the learning takes place in an asynchronous manner.

4. Synchronous Small Private Online Courses (SSPOCs): Like the ASPOCs, the number of students is limited, and require participants to follow the lessons in real time.

AMOOCs are available today and many academic institutions are offering asynchronous courses for massive audiences, consisting of both national and international students, who are geographically dispersed. This trend is also starting 
to get some traction in the industry, e.g., training courses and company announcements for worldwide workers in the automobile industry. Synchronous versions of these, SMOOCs, are not prevalent yet, mainly due to technology bandwidth limitations and international time zones. ASPOCs and SSPOCs are the most common today in academia and are gaining popularity due to the available technical features and capabilities, user friendly robust interfaces, and mainly due to the conveniences to the students. This research is based on the analysis of STEM courses offered and taught in-person onsite and the same courses offered in the SSPOC environment. Plans are currently in place, and work is in progress, to move these courses to the ASPOC platform.

\section{OBSERVED DIFFERENCES BETWEEN ONSITE AND ONLINE CLASSES}

The authors of this paper are engaged in teaching research and have published several papers describing their teaching experiences and findings. Table 1 presents some important differences they have observed from onsite and online classes.

Table 1. Some Differences Between Onsite and Online Classes

\begin{tabular}{|c|c|c|}
\hline & ON & $\overline{\mathrm{OI}}$ \\
\hline 1 & $\begin{array}{l}\text { Most instructors prefer onsite teaching because they } \\
\text { are used to it and can express their physical } \\
\text { expressions and enjoy interactions with students in } \\
\text { the classroom. }\end{array}$ & $\begin{array}{l}\text { Some instructors prefer online teaching because } \\
\text { they are well trained and comfortable with different } \\
\text { technologies/tools in online teaching. }\end{array}$ \\
\hline 2 & Instructors of older generation prefer onsite class. & $\begin{array}{l}\text { Instructors of younger generation prefer online } \\
\text { classes. }\end{array}$ \\
\hline 3 & $\begin{array}{l}\text { rs give lectures from their experiences and } \\
\text { s. }\end{array}$ & $\begin{array}{l}\text { Instructors prepare lectures carefully using most } \\
\text { advanced teaching tools/technologies. }\end{array}$ \\
\hline 4 & \begin{tabular}{|lllll}
$\begin{array}{l}\text { Lecture materials } \\
\text { unstructured. }\end{array}$ & are semi structured & or \\
\end{tabular} & Materials are structured and \\
\hline 5 & $\begin{array}{l}\text { Lectures are not recorded, and students cannot } \\
\text { replay and listen to the lectures. }\end{array}$ & \\
\hline 6 & do not ask questions. & $\begin{array}{l}\text { can be invisible } \\
\text { text/chat or using }\end{array}$ \\
\hline 7 & y due & \\
\hline 8 & efforts in & ing \\
\hline 9 & ors while & \\
\hline 10 & $\begin{array}{l}\text { signments, exams and } \\
\text { re common and easy. }\end{array}$ & $\begin{array}{l}\text { Students are at different geographical locations and, } \\
\text { invariably, do not know each other. They have } \\
\text { limited opportunity for copying/cheating in the } \\
\text { assignments, exams, and quizzes from classmates. }\end{array}$ \\
\hline 11 & Instructors know who are taking the & $\begin{array}{l}\text { In most cases, instructors do not know who are } \\
\text { taking the exams. }\end{array}$ \\
\hline 12 & $\begin{array}{l}\text { Student } \\
\text { classes }\end{array}$ & extra \\
\hline 13 & $\begin{array}{l}\text { Group projects are less successful. Students write } \\
\text { report carefully but take less preparations for } \\
\text { presentations and they use mostly power point } \\
\text { slides. }\end{array}$ & $\begin{array}{l}\text { Group projects are successful because students are } \\
\text { careful to write the report and video record their } \\
\text { presentations using different audiovisual } \\
\text { technologies. }\end{array}$ \\
\hline 14 & \begin{tabular}{|l}
$\begin{array}{l}\text { Projects requiring hardware are possible for } \\
\text { students. }\end{array}$ \\
\end{tabular} & $\begin{array}{l}\text { Theoretical or simulation group projects are usually } \\
\text { doable and practical. }\end{array}$ \\
\hline 15 & $\begin{array}{l}\text { Hands-on lab experiments are convenient in } \\
\text { classroom for limited class time only. }\end{array}$ & $\begin{array}{l}\text { Circuit simulations using pre-developed } \\
\text { commercial software are helpful and students can } \\
\text { do the lab work anytime they want to and can repeat } \\
\text { experiment as many times as needed. }\end{array}$ \\
\hline
\end{tabular}




\begin{tabular}{|l|l|l|}
16 & $\begin{array}{l}\text { Student peer evaluations are biased in most cases } \\
\text { because they know each other and develop some } \\
\text { relationships. }\end{array}$ & $\begin{array}{l}\text { Students peer evaluations are unbiased because, in } \\
\text { most cases, they do not know each other and make } \\
\text { more accurate judgement. }\end{array}$ \\
\hline 17 & $\begin{array}{l}\text { Transparent grading process has less impact. } \\
\text { Transparent grading process is very important. }\end{array}$ \\
\hline 18 & $\begin{array}{l}\text { Instructor's feedback/comments on students' work } \\
\text { are expected by some students. }\end{array}$ & $\begin{array}{l}\text { All students are seriously expecting instructor's } \\
\text { feedback/comments on their work. }\end{array}$ \\
\hline 19 & $\begin{array}{l}\text { Communications and interactions among the } \\
\text { students and instructors take place mostly during the } \\
\text { class time and office hours. }\end{array}$ & $\begin{array}{l}\text { Students expect fast and accurate instructor } \\
\text { response. Otherwise, students feel disconnected and } \\
\text { unsecure. Communications and interactions among } \\
\text { the students and instructors take place 24/7. }\end{array}$ \\
\hline 20 & $\begin{array}{l}\text { Both students and instructors spend moderate time } \\
\text { preparing for their classes. }\end{array}$ & $\begin{array}{l}\text { In all cases, both students and instructors spend } \\
\text { more time preparing for the online class than the } \\
\text { onsite classes. }\end{array}$ \\
\hline $\begin{array}{l}\text { Instructors have less options to arrange guest } \\
\text { lectures. }\end{array}$ & $\begin{array}{l}\text { In most classes, instructor can invite subject matter } \\
\text { experts and industry professionals and schedule } \\
\text { guest lectures through online platforms for higher } \\
\text { learning. }\end{array}$ \\
\hline
\end{tabular}

\section{BEST PRACTICES FOR ONLINE CLASSES TO PROMOTE STUDENT ENGAGEMENT}

In a traditional onsite in-person class environment, the student-teacher interactions and lively interactions between students are probably the biggest contributors to the student learning. These real-time interactions encourage the learners to reflect, think critically, and, most importantly, be able to logically articulate their arguments during discussions. This mental process of applying their creativity to understand the application helps them to reflect on the content and make the learning more permanent. For faculty teaching online, one of the challenges is finding ways to create the same level of real-time interactions between students and teacher, and among students themselves. The course content must encourage learner reflection and critical thinking at each level of understanding. Most engineering students today are tech savvy and can get the information they need. The ability to browse and learn on their own has become a growing expectation for many digital natives. Courses should be designed with content and questions that guide the learners in the right direction and make them reflect and think. Open-ended questions that learners can experiment with, reflect, and think critically by applying the concepts that they are learning, encourages curiosity. This makes the learning process fun and the learning more permanent. This section describes the best practices in the design and delivery of the online content that may be used to promote reflective and critical thinking in learners.

- Time Management for Reflection and Critical Thinking: The content must be organized to promote and encourage learners to manage time effectively and productively. The course site and the syllabus should clearly set time limits on instructor availability, discussion times, and feedback times. Do not always be available to learners. Knowing the limited availability of the instructors encourage the learners to reflect on their own and think more deeply about their own learning process. Getting familiar with and using available technologies for content distribution, student submissions, grades, and other technological operations are becoming standard practices. Once familiar, with these tools and applications, the instructor are more organized and this also helps learners to manage time effectively.

- Content to Encourage Reflection for Diverse Group of Learners: Online education is global and used by learners from different categories. Content should target students with a broad range in ability, learning style, languages, age group, work experience, time commitments, and other personal circumstances. Course Learning Outcomes (CLOs) must be developed that are measurable and contain assessment criteria. These inform the students the expectations and how these expectations are to be measured. The content needs to contain resources, applications, examples, and links to relevant events that are easily accessed from the student's locations. Given the existing online resources, there is no need to reinvent. Sources such as MERLOT (http://merlot.org), Khan Academy (http://www.khanacademy.org), and YouTube (http://youtube.com) will improve the content significantly to promote reflective and critical thinking.

- Small Target Pieces for Reflections: Learners may be engaged with the course material at multiple times and over multiple sessions, creating a stop and start affect that should be addressed in the content design. Course creators should be aware of and design accordingly so that students experience the ability to interact with smaller pieces or sequences of material so they can continue to make effective use of the asynchronous learning experience [34-35]. By packaging the content in small sequential lessons, student can engage and reflect in small steps, thus proceeding to the next step only after the previous step is reflected upon. This encourages the learner to reflect and take responsibility of their learning process. 
- Closing Activity to Encourage Critical Thinking: A good closing activity for the course is important for making the learning more enjoyable and permanent. This could be in the form of a project or an assignment that covers most of the topics the learners have been introduced to. This encourages the student to reflect upon the relations between the different concepts that they have learnt and helps make learning relevant. Closing activities should include a mix of real world or simulated real world practical applications with effective use of scholarly research in which to develop the practical demonstrations of CLOs.

- Structured Course Content and User-Friendly LMS Interfaces: Clear course navigation, based on learning objectives, is critical. One of the advantages of online learning is that students have all the material at their fingertips, which makes it easy to review as needed, but that only works if the process of locating it is easy, user-friendly, and intuitive.

- Automated Data Collections and Assessments Whenever Possible: Best Practices in Student Assessment and Data Evaluation Best Practice recommendations for the assessment of student learning in an online environment include data collection and assessment through an automated process that uses several methods and applies specific standards for student learning. Automated data collection and assessments also helps timely feedback, and this is very encouraging and rewarding to the students.

- Encourage Collaboration and Teamwork: Collaboration, teamwork, and learning to be a team player are important qualities and abilities for the $21^{\text {st }}$ century workforce. Students learn these with assignments, projects, and discussions during their course time. These are challenges in an online environment due to possible locations, time-zones, and individual availabilities, but should be strongly encouraged. Students learn invaluable lessons of 'getting the project done' and individual responsibilities. Online discussion forums are effective ways to facilitate interactions and learning in the online classrooms, in part, due to their ability to promote constructivist and critical thinking and distributing knowledge among all the students in the class.

- Design Plagiarism-Proof Assessments: Plagiarism has been a problem in academia for a long time. This is especially significant in an online environment. Instead of trying to plan to methods to minimize plagiarism, assignments, projects, and exams, can be designed that make them plagiarism-proof. Innovative ways like case studies, design projects, etc. may be used to minimize students getting ready answers and help online and on social media.

- Choice of Educational Technologies and Course Management Tools: One of the most important elements of planning and managing online courses is to recognize the fact that although there is a wide array of Learning Management Systems (LMS) available for online teaching, not all these technologies are appropriate matches to the subject taught. This is especially important for STEM courses containing technical content and hands-on work. Attention should be placed on web page design and gathering all content in folders for ease of access for learners. Organization of content in sections helps and linking relevant topics is a good practice. Use of audio video links is encouraged and these short clips are effective for student learning.

\section{ANALYSIS OF A STEM COURSE}

Over the past two decades, the authors have taught a variety of engineering, computer science, and technology graduate and undergraduate classes, including electrical circuit courses in both online and onsite modalities. They have collaborated with other educators and published articles/papers to present their teaching experiences and teaching related research findings [22-24]. Recently, these authors have published two articles on effectiveness of online teaching for computer science courses and concluded some positive results [36-37]. For online classes, the university had earlier adopted the eCollege delivery platform with ClassLivePro, and, currently, the university is using Blackboard with Collaborate Ultra. Recently, the university started providing the same version of the online course shell called eCompanion for every onsite class. This change has improved consistency of courseware content for instructors for both onsite and online delivery, and improved student learning as instructors have more latitude to focus on multiple avenues of delivery through multimode teaching methods. In this paper, a case study is presented with an undergraduate level electrical circuit course offered both online and onsite. Sixteen graduate level circuit classes (eight onsite and eight online) are considered for this analysis.

In online classes, the instructor used a Microsoft Surface Book (Tablet) for free handwriting, circuit drawing for analysis required for all classes. Electrical circuits were analyzed to solve problems in multiple ways step-by-step, showing students the tablet desktop using Blackboard Collaborate Ultra. These enabled students get the benefits of an onsite class during these online sessions. The real-time collaborative nature of an onsite classroom was replicated, enhancing the student learning experience. These dynamic two-way online sessions, as opposed to using static PowerPoint presentations, for these conceptually intense circuit classes, were a significant value-add. The average GPAs for all the circuit classes analyzed for this research were within the university target. The instructor gave two two-hour lectures per week using a microphone through Collaborate in the Blackboard and drew circuits, wrote important/critical notes on the Microsoft Surface Tablet screen with a 
smart pen and shared the tablet desktop with the students. Students could see all the classroom activities on their computers, listen to lectures using earphones and ask questions through the microphone or chat texts. All these instructional activities were recorded and saved in eCollege and Blackboard. These recorded sessions were made available 24/7 to the students for download and replay at the students' convenience. Instructor responses to student inquiries/questions were prompt and proactive. Students could also contact the instructor through email, phone, and in-person during the posted office hours - just like the onsite students.

At NU, an end of course survey for all classes is offered, and all students are expected and encouraged to participate. The survey form used by NU has a total of 22 questions in three major areas: 1) Student Self-Assessment of Learning: 7 questions, 2) Assessment of Teaching: 12 questions and 3) Assessment of Course Content: 3 questions. This survey form also allows students to write their comments. Survey data is analyzed by the NU Office of the Institutional Research and Assessment (OIRA). A summary of the survey data with student comments are made available to the respective instructors, department chairs, and school deans for review and comments. The authors of this paper always review their course survey reports from OIRA carefully and adjust their future teaching plans by improving their pedagogical approach to teaching and adopt different or modified multimode techniques as appropriate.

\section{RESULTS AND DISCUSSIONS}

Table-1 presents some important information and experiences these authors observed and collected from both onsite and online classes. Table-2a and Table- $2 b$ depict the data of instructor's teaching and students' learning for eight onsite and eight online EGR230 classes. The EGR230 Electrical Circuits and Systems is an introductory engineering course which is required for all undergraduates engineering technology degree programs at National University. Students consider this as a challenging class for non-electrical engineering technology majors. Table-2a presents the class average values of learning and teaching for eight onsite classes from 2007 to 2019, and Table-2b for the eight online EGR230 classes from 2008 to 2021 academic years. Table- 3 depicts the overall average values of teaching and learning with the corresponding standard deviations. Figure-1a is the graphical representation of learning and teaching for eight EGR230 Onsite Classes during 2007-2019 academic years. Fgure-1b is the graphical representation of learning and teaching for eight EGR230 Online Classes during 2008-2021 academic years. Figure-2a is the comparison of student self-assessment of learning scores between onsite and online. Figure$2 \mathrm{~b}$ is the comparison scores on instructor's teaching performance for the eight onsite and eight online EGR230 Electrical Circuits and Systems classes. These results indicate that the instructor is consistently receiving high scores on teaching and students expressing their high satisfactions of learning.

Table-2a. Average Values of Teaching and Learning for Onsite Circuit Classes 2007-2019 Academic Years.

$\begin{array}{cccc}\text { Course No. } & \text { Term } & \text { Learning } & \text { Teaching } \\ \text { *EGR313 } & \text { FY07 } & 4.69 & 4.86 \\ \text { *EGR313 } & \text { FY08 } & 3.80 & 4.16 \\ \text { *EGR313 } & \text { FY09 } & 4.00 & 4.50 \\ \text { *EGR313 } & \text { FY09 } & 3.80 & 4.16 \\ \text { *EGR313 } & \text { FY10 } & 4.00 & 4.50 \\ \text { *EGR313 } & \text { FY11 } & 3.84 & 3.69 \\ \text { EGR230 } & \text { FY18 } & 4.31 & 4.37 \\ \text { EGR230 } & \text { FY19 } & 4.67 & 4.94\end{array}$

Table-2b. Average Values of Teaching and Learning for Online Circuit Classes 2008-2021 Academic Years.

$\begin{array}{cccc}\text { Course No. } & \text { Term } & \text { Learning } & \text { Teaching } \\ \text { *EGR313 } & \text { FY08 } & 4.47 & 4.63 \\ \text { *EGR313 } & \text { FY09 } & 4.64 & 4.47 \\ \text { *EGR313 } & \text { FY10 } & 3.69 & 3.84 \\ \text { *EGR313 } & \text { FY11 } & 4.30 & 4.35 \\ \text { EGR230 } & \text { FY13 } & 4.00 & 4.31 \\ \text { EGR230 } & \text { FY18 } & 4.95 & 4.67 \\ \text { EGR230 } & \text { FY21 } & 4.57 & 4.60 \\ \text { EGR230 } & \text { FY21 } & 5.00 & 5.00\end{array}$

*EGR313 was the former course number of EGR230. 
Table-3. Average Values and Standard Deviations of Teaching and LearningOnsite Classes: 2007-2019 and Online Classes: 2008-2021 Academic Years.

\begin{tabular}{|c|c|c|c|c|}
\hline Teaching Mode & Learning Avg & Std Dev & Teaching Avg & Std Dev \\
\hline Onsite & 4.139 & 0.373 & 4.398 & 0.404 \\
\hline Online & 4.453 & 0.448 & 4.484 & 0.338 \\
\hline
\end{tabular}

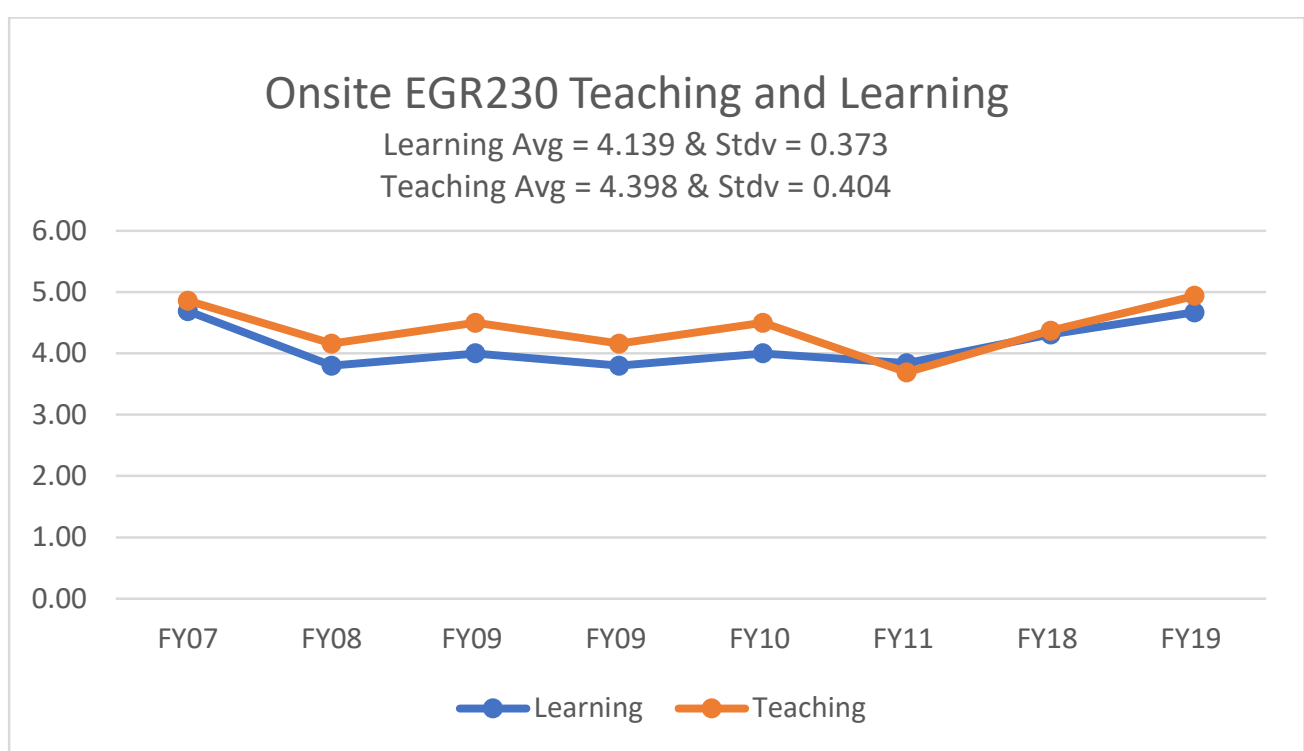

Figure-1a. Graphical Representations of Teaching and Learning for EGR230 Onsite Classes: 2007-2019 Academic Years.

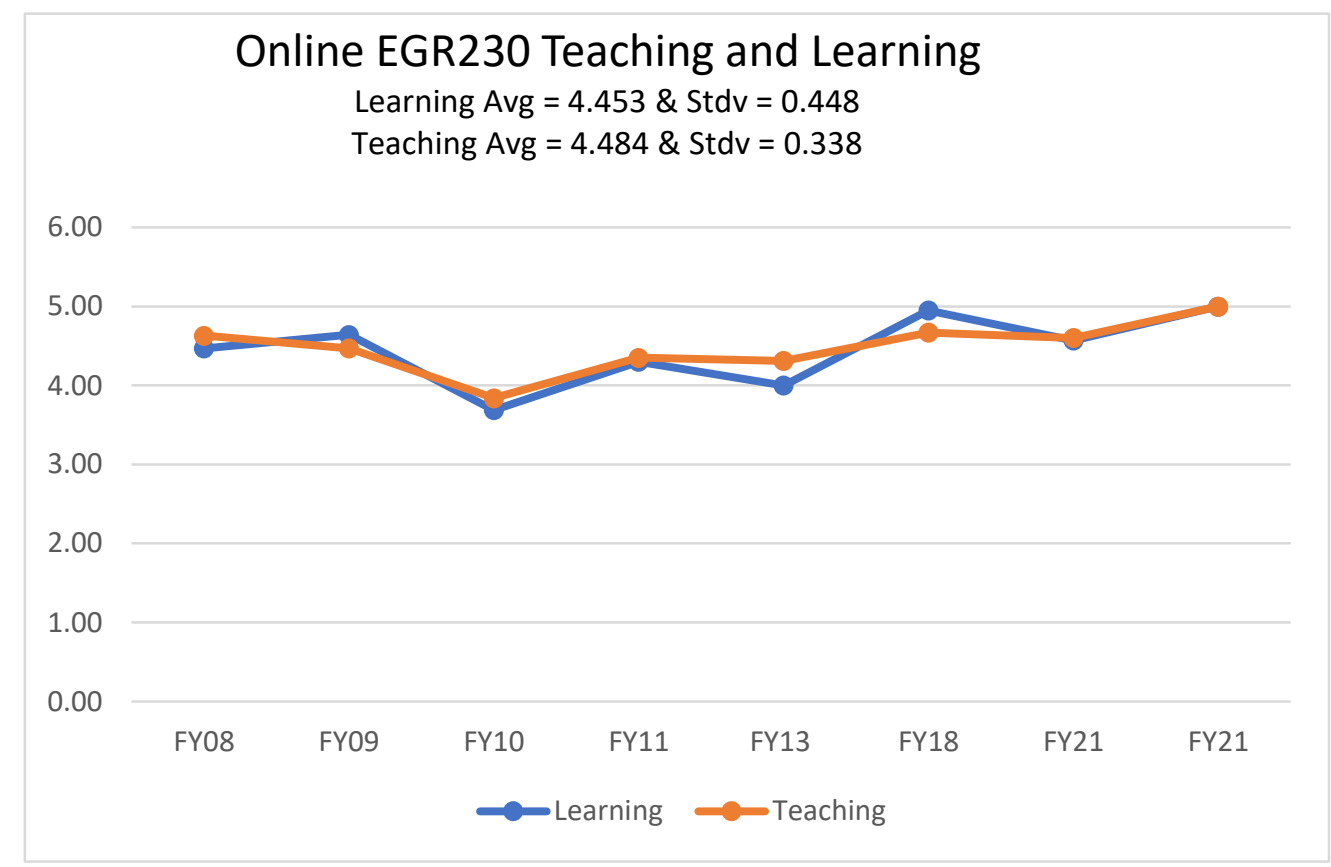

Figure-1b. Graphical Representations of Teaching and Learning for EGR230 Online Classes: 2008-2021 Academic Years. 


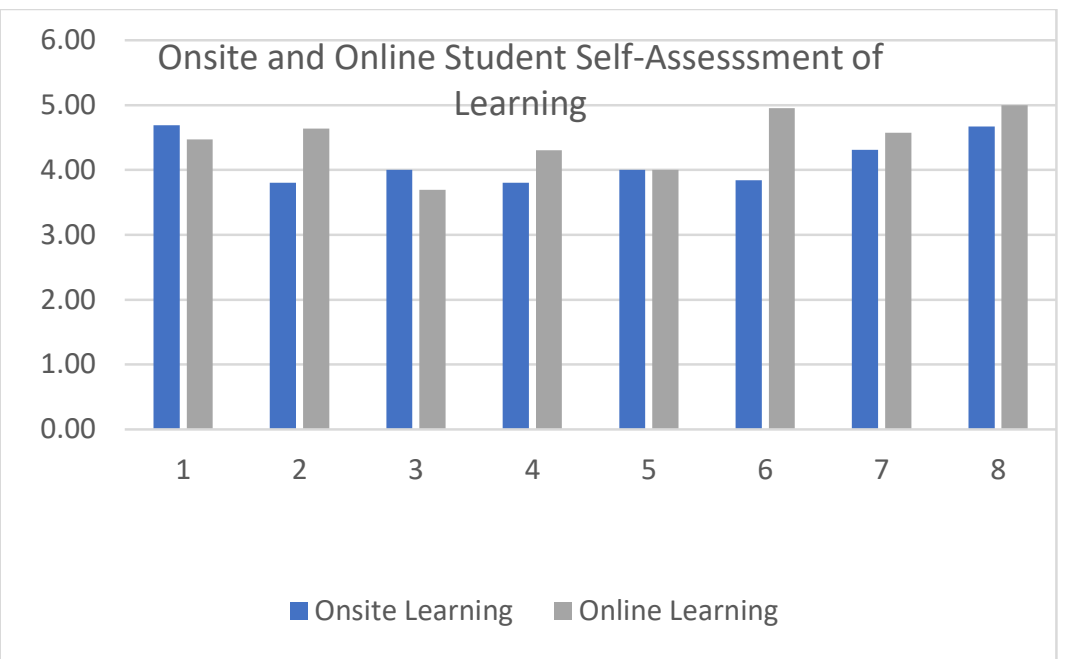

Figure-2a: Comparison of Student Self-Assessment of Learning from EGR230 Onsite and Online Classes

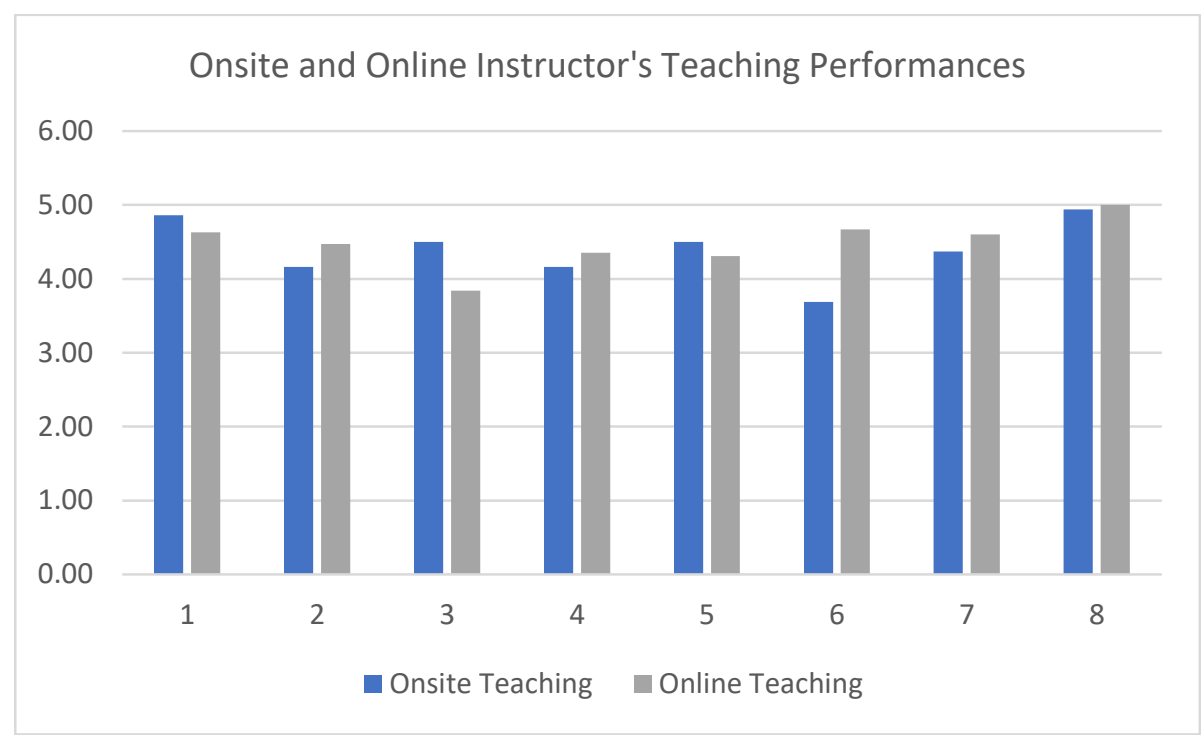

Figure-2b: Comparison of Instructor's Teaching Performance of EGR230 Onsite and Online Classes

Summary of these student self-assessments of learning scores in Figure-2a indicates that the students consistently expressed appreciation for the student-teacher friendly interactions, conducive learning environment, teacher's approach to students, teaching style, active student involvement, and overall learning process. Many students explicitly stated in their comments that the instructor did an excellent job, explained the topics very well, and presented difficult materials in a simple and understandable format. Following are a few comments made by students anonymously at the end of course survey and copied from NU database:

"Dr. John Doe is_without question_the smartest and most knowledgeable person I have ever met. I have had a few professors who were very intelligent_ but they did not impart their knowledge and experience to the extent that Dr. John Doe did. He immediately made it known that this course was his sole priority_ which was different from all other professors who had other jobs and other priorities. Dr. John Doe responded to all emails within a few hours at most_and normal responses were within the hour. The depth and scope of his expertise were evident_and I feel as though I gained as much from the extra bits of information he gave as I journey at National University."

"Great instructor_the class was hard work, but it paid off and I feel like I've learned a lot during this class."

Figure- $2 b$ is the comparison of the instructor's teaching performance scores for the same set of eight onsite and eight online EGR230 Electrical Circuits and Systems classes. These results indicate that the instructor is consistently receiving high 
scores on teaching. The instructor used well thought out answers. Instructor also encouraged students to ask questions and answered them using different methods and technologies during the classroom presentations including audio, video, graphic, animated simulations, handouts, and appropriate references. Classes were organized, structured, and well managed. Class time was utilized wisely and interactively with hands on activities. Instructor asked higher level challenging questions to students. Instructor provided a very conducive learning environment where students could get deeply involved and engaged in the class with both instructor and other fellow students.

\section{CONCLUSION}

From the graphs in Figure-2a and Figure-2b, it is concluded that the learners experience is basically the same for both onsite and online classes. In some cases, students' learnings and the perceived benefits of electrical circuit classes are better in online classes. Students' satisfactions of both online and onsite classes were observed to be almost the same. The Grade Point Average (GPA) for all classes in this study was approximately 2.75 (grade: B-), indicating appropriate rigor. The number of students enrolled in each of the classes were approximately 25. From the graphs in Figure-1a and Figure-1b it is observed that the online teaching and learning curves are steadier than the onsite. Standard deviations for both the onsite and online modes of deliveries were similar. The average students' learning and instructor's teaching were higher in the online mode. Instructor provided online live session using either Zoom or Blackboard Collaborate with a Microsoft Surface Book for freehand circuit drawing, writing critical information/notes, and recording all interactive activities. Students who needed to replay the recordings could do that anytime from anywhere. Most NU students are employed full-time and have families. Because of tight schedule many of these busy students could not attend the live sessions during the scheduled time, but they were able to download the recordings anytime from anywhere to get the same benefits. During the live sessions, this instructor always asked questions and expected answers from the students. Some students were deeply engaged in the live sessions and participated actively. The instructor provided two 2-3 hours live sessions per week for all the online classes. In most classes, the instructor held extra live sessions per students' request, and provided review sessions before the exams for better preparations. In addition to the pre-developed online course materials, this instructor provided extra resources/materials for higher learning. Most online students appreciated these extra resources and extra efforts made by the instructor. As a matter of fact, the instructor spent more time for online classes than the onsite classes, to create an online environment where students are taken care of, and help is available when needed. For these online classes, communications and interactions among the students and instructors took place $24 / 7$.

Finally, it can be concluded that the students get the same or better benefits in these STEM electrical circuit topics, including better learning experience, through online classes. Our reviews and reflections on the study of these classes suggest that opportunities for online education can be made attractive to students given adequate attention to student needs. Online classes can be more valuable and effective for students if the following are carefully considered: 1) Develop a user-friendly course shell with higher clarity and well-structured contents for online course. Students should have the feelings that all the materials are readily available, and they can easily navigate and review as needed. 2) Add some personal touches among students and instructor with audio and video technologies. Create a conducive learning environment where students are not hesitant of sharing and showing their ideas and activities. Instructor should provide accurate, precise, and timely feedback on students' work. 3) Provide continuing support and help for individual student needs. It is very important for the instructors to develop their own online teaching skills, adapting new technologies and teaching tools, and develop strategies for maximum help for students in their learning process. The online courses allow instructor for more options and opportunities to adjust course contents and/or better structure during the course offering period based on the students' feedback and comments. 4) Course expectations, course requirements, full schedule, all deadlines, and grading process must be clear and transparent.

The outcomes of this research contribute towards NU's plans to include online offerings of all courses to deal with the challenges emerging from the "new normal" environment due to the Corona pandemic. Future research may be explored for contributing towards developing robust online learning systems that may be available to a wide spectrum of engineering and computer science learners in both synchronous and asynchronous modes.

\section{ACKNOWLEDGEMENTS}

The authors gratefully acknowledge the help and support received from the administration, staff, and faculty members in the Department of Engineering and Computing at NU, during the continuing research on this subject and the preparation of this document. 


\section{REFERENCES}

[1] Wikipedia. Online Learning in Higher Education. Retrieved from Wikipedia, the free encyclopedia. Online learning in higher education - Wikipedia

[2] Kentnor, H. (2015). Distance education and the evolution of online learning in the United States. Curriculum and Teaching Dialogue. 17: 21-34.

[3] Rowan, R. (1983). Executive Ed. at Computer U. Fortune, March 7, 1983; Feenberg, Andrew (1993). "Building a Global Network: The WBSI Experience," in L. Harasim, ed., Global Networks: Computerizing the International Community, MIT Press, pp. 185-197.

[4] Miller, G., Benke, M., Chaloux, B., Ragan, L.C., Schroeder, R., Smutz, W., Swan, K. (2014). Leading the e-learning transformation of higher education. Sterling, Virginia: Stylus. ISBN 978-1-57922-796-8.

[5] "Company Overview of Trident University International". www.bloomberg.com.

[6] "Trident University International LLC Overview". www.bbb.org.

[7] Radford, A.W. (2011). "Learning at a Distance: Undergraduate Enrollment in Distance Education Courses and Degree Programs". nces.ed.gov.

[8] National Center for Education Statistics (2016). "Digest of education statistics, 2014". nces.ed.gov. U.S. Department of Education.

[9] Haynie, D. (January 30, 2015). "Experts debate graduation rates for online students". U. S. News \& World Report.

[10] Jazzar, M. (December 7, 2012). "Online student retention strategies: A baker's dozen of recommendations". Faculty Focus.

[11] https://www.timeshighereducation.com/features/will-coronavirus-make-online-education-go-viral

[12] https://www.nytimes.com/2020/03/18/opinion/college-education-coronavirus.html

[13] https://www.npr.org/2020/03/19/817885991/panic-gogy-teaching-online-classes-during-the-coronavirus-pandemic

[14] Aristovnik A, Keržič D, Ravšelj D, Tomaževič N, Umek L (October 2020). "Impacts of the COVID-19 Pandemic on Life of Higher Education Students: A Global Perspective". Sustainability. 12 (20): 8438. doi:10.3390/su12208438.

[15] Means, B., Toyama, Y., Murphy, R., Bakia, M., and Jones, K. (2010 September). Evaluation of Evidence-Based Practices in Online Learning: A Meta-Analysis and Review of Online Learning Studies, US Department of Education, Office of Planning, Evaluation, and Policy Development. Retrieved on June 01, 2020, from https://www2.ed.gov/rschstat/eval/tech/evidence-based-practices/finalreport.pdf

[16] Allen, E. and Seaman, J. (2013 January). Changing Course Ten Years of Tracking Online Education in the United States, Babson Survey Research Group and Quahog Research Group, LLC. Retrieved on June 01, 2020 from https://www.onlinelearningsurvey.com/reports/changingcourse.pdf

[17] Army, A.B. (2014). The Impact of WhatsApp Mobile Social Learning on the Achievement and Attitudes of Female Students Compared with Face-to-Face Learning in the Classroom, European Scientific Journal, vol.10, No.22. Retrieved on April 20, 2020, from https://eujournal.org/index.php/esj/article/view/3909

[18] Jaggars, S. (2014). Choosing Between Online and Face-to-Face Courses: Community College Student Voices, American Journal of Distance Education, Volume 28, 2014 - Issue 1. Retrieved on June 02, 2020 from https://ccrc.tc.columbia.edu/media/k2/attachments/online-demand-student-voices.pdf

[19] Eryilmax, M. (2015). The Effectiveness of Blended Learning Environments, Contemporary Issues in Education Research (CIER), 8(4), 251-256. Retrieved on April 20, 2020 from https://www.clutejournals.com/index.php/CIER/article/view/9433

[20] Illinois Online, University of Illinois, Urbana, IL. Retrieved on January 05, 2020 from https://online.illinois.edu/

[21] Delivering High-Quality Instruction Online in Response to COVID-19, Online Learning Consortium, Funded by Bill and Malinda Gates Foundation. Retrieved on June 10, 2020 from https://onlinelearningconsortium.org/tools/deliveringhigh-quality-instruction-in-response-to-covid-19-faculty-playbook/

[22] Uhlig, R., Jawad, S., Dey, P., Amin, M., and Sinha, B. (2018). Enriching Responsiveness to Enhance Student Learning in Online Courses. 8th Annual - 2018 STEM/STEAM Education Conference, Prince Waikiki, Hawaii. June 6-8, 2018. https://huichawaii.org/

[23] Uhlig, R., Jawad, S., Dey, P., Amin, M., and Sinha, B. (2019). Enhancing Learning Experience in Online Courses through Enriched Responsiveness. International Journal of Advanced Engineering and Management Research (IJAEMR 2019), Vol.4, No.3, Pages: 11-22. ISSN: 2456-3676. http://ijaemr.com/view4.php?issue=3

[24] Uhlig, R., Sinha, B., Jawad, S., Dey, P., and Amin, M. (2017). Enhancing Student Collaboration for Improved Learning, Journal of Modern Education Review, Volume 7, No. 8, pp. 529-544 Doi: 10.15341/jmer (2155-7993)/08.07.2017/001 (c) Academic Star Publishing Company. http://www.academicstar.us/UploadFile/Picture/2018-2/20182241536250.pdf

[25] Giesbers, B., Rienties, B. Tempelaar, D. and Gijselaers, W. (2014-02-01). "A dynamic analysis of the interplay between asynchronous and synchronous communication in online learning: The impact of motivation". Journal of Computer Assisted Learning. 30 (1): 30-50. doi:10.1111/jcal.12020. ISSN 1365-2729. 
[26] Douglas Business School (2020). Online learning is more flexibility than traditional university college settings. March 28,2020

[27] Stewart, Anissa R., Harlow, Danielle B., and DeBacco, Kim (2011). "Students' experiences of synchronous learning in distributed environments". Distance Education. 32 (3): 357-381.

[28] Hrastinski, Stefan (2008). "Asynchronous and synchronous e-learning". Educause Quarterly. 4: 51-55.

[29] Hanna, Donald E., Glowacki-Dudka, Michelle, and Conceicao-Runlee, Simone (2000). 147 practical tips for teaching online groups. Madison, Wisconsin: Atwood Publishing.

[30] Lieblein, Edward (2000). "Critical factors for successful delivery of online programs". Internet and Higher Education. 3: 161-174.

[31] Johnson, Henry M. (2007). "Dialogue and the construction of knowledge in e-learning: Exploring students' perceptions of their learning while using Blackboard's asynchronous discussion board" (PDF). European Journal of Open, Distance and E-Learning. 10 (1). Retrieved 18 August 2020.

[32] Ho, Chia-Huan, and Swan, Karen (2007). "Evaluating online conversation in an asynchronous environment: An application of Grice's Cooperative". Internet and Higher Education. 10 (1): 3-14.

[33] "Andreas Kaplan (2017) Academia Goes Social Media, MOOC, SPOC, SMOC, and SSOC: The digital transformation of Higher Education Institutions and Universities, in Bikramjit Rishi and Subir Bandyopadhyay (eds.), Contemporary Issues in Social Media Marketing, Routledge".

[34] Liqiu, W. (2011). Formative Assessment in Classrooms: Operational Procedures. Journal of Language Teaching \& Research, 2(1), 99-103. doi: 10.4304/j1tr.2.1.99-103

[35] Patron, H. and Lopez, S. (2011). Student Effort, Consistency, and Online Performance. [Article]. Journal of Educators Online, 8(2), 1-11.

[36] Amin, M., Dey, P., and Sinha, B. (2020). Effectiveness of Online Teaching Paradigm on Learning Experiences in Database Courses, Vol 36, No. 2, ACM Digital Library.

[37] Dey, P., Sinha, B., and Amin, M. (2020). Supporting Asynchronous Learners with Multiple Representations, Vol 36, No. 2, ACM Digital Library. 